\title{
Aero-elastic wind turbine design with active flaps for AEP maximization
}

\author{
Michael K. McWilliam, Thanasis K. Barlas, Helge A. Madsen, and Frederik Zahle \\ DTU Wind Energy, Frederiksborgvej 399, 4000 Roskilde, Denmark \\ Correspondence: Michael K. McWilliam (mimc@dtu.dk)
}

Received: 7 November 2017 - Discussion started: 17 November 2017

Revised: 2 February 2018 - Accepted: 16 February 2018 - Published: 4 May 2018

\begin{abstract}
In optimal wind turbine design, there is a compromise between maximizing the energy producing forces and minimizing the absolute peak loads carried by the structures. Active flaps are an attractive strategy because they give engineers greater freedom to vary the aerodynamic forces under any condition. Flaps can be used in a variety of different ways (i.e. reducing fatigue, peak loads), but this article focuses on how quasi-static actuation as a function of mean wind speed can be used for annual energy production (AEP) maximization. Numerical design optimization of the DTU 10 MW reference wind turbine (RWT), with the HAWTOpt2 framework, was used to both find the optimal flap control strategy and the optimal turbine designs. The research shows that active flaps can provide a $1 \%$ gain in AEP for aero-structurally optimized blades in both add-on (i.e. the flap is added after the blade is designed) and integrated (i.e. the blade design and flap angle is optimized together) solutions. The results show that flaps are complementary to passive load alleviation because they provide highorder alleviation, where passive strategies only provide linear alleviation with respect to average wind speed. However, the changing loading from the flaps further complicates the design of torsionally active blades; thus, integrated design methods are needed to design these systems.
\end{abstract}

\section{Introduction}

The size of wind turbines has been increasing rapidly over the past years. Rotors of more than $160 \mathrm{~m}$ in diameter are already commercially available. By focusing on lowering the cost per kilowatt hour, new trends and technological improvements have been primary targets of research and development. One main focus (among others) is on developing new technologies (Madsen et al., 2014) which are capable of considerably reducing the loads and increasing annual energy production (AEP) for wind turbines.

New concepts for dynamic load reduction are focusing on both a faster and detailed load control, compared to existing individual blade pitch control, by utilizing active aerodynamic control devices distributed along the blade span (Bernhammer et al., 2014; Johnson et al., 2010; Barlas and van Kuik, 2010). Such concepts are generally referred to as smart rotor control, a term used in rotorcraft research. Over the past years, these concepts have been investigated for wind turbine applications in terms of conceptual and aero-elastic analysis, small-scale wind tunnel experiments and, recently, field testing (van Wingerden et al., 2011; Castaignet et al., 2014). For a review of the state of the art in the topic, the reader is referred to Bernhammer et al. (2014), Johnson et al. (2010) and Barlas and van Kuik (2010).

So far, results from numerical and experimental analysis, mostly focusing on trailing edge flaps, have shown a considerable potential in fatigue load reduction (Barlas, 2011; Bergami, 2013). Existing work has focused on application of active flaps on existing blade designs (Barlas et al., 2016a; Madsen et al., 2015), implicitly showing the potential for reduction of cost of energy. Only recently have researchers started to investigate the potential of an optimized blade design integrating the use of active flaps. Barlas et al. (2016b) explored optimal blade design when flaps are integrated for fatigue load reduction. This work only looked at one flap control strategy, so there remains questions on the impact of other control strategies. Chen et al. (2017) performed full aero-elastic blade design, similar to the work here, with an 
(a)

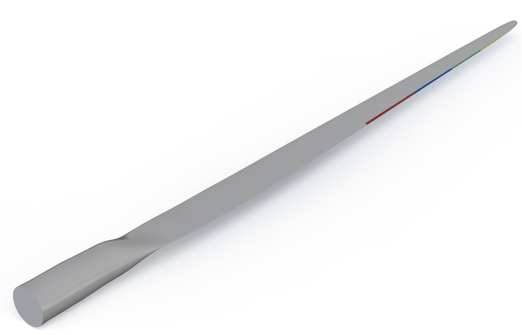

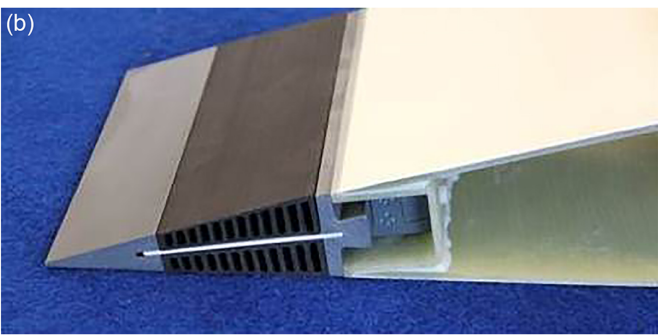

Figure 1. Active flaps on a wind turbine blade.

active flap to control fatigue damage. Smit et al. (2016) optimized the flap size and control to maximize power. This work only looked at the flap sizing with steady-state aerodynamic models and did not look at the aero-elastic blade design as this article presents.

Rotor design is an inherently multidisciplinary design problem due to the complex coupling between aerodynamics, structural dynamics and control. To properly assess the impact of new technology on rotor design, one must consider all disciplines simultaneously. For example, load reduction technology is typically used to increase AEP by increasing the rotor diameter. Multidisciplinary design optimization (MDO) can generate aero-elastically optimized blade designs by considering all the disciplines in the optimization simultaneously. In the recent years several MDO frameworks have been developed to perform wind turbine multidisciplinary optimization design (Bottasso et al., 2012; Ashuri et al., 2014; Merz, 2015a, b; Fischer et al., 2014; Ning et al., 2014; McWilliam, 2015). In this work an optimization framework called HAWTOpt2 (Zahle et al., 2016) is utilized which enables concurrent optimization of the structure and outer shape of a wind turbine blade. This tool builds on the experience gained with the HAWTOpt2 code (Fuglsang and Madsen, 1999) but is otherwise a completely new code base written in the Python programming language.

An example layout of the blade planform incorporating active trailing edge flap sections in shown in Fig. 1a, along with a detailed example of a flap in Fig. $1 b$.

The overall idea is that between 65 and $95 \%$ of the blade span, the trailing $10 \%$ of the profile will be replaced with an active flap (Madsen et al., 2014). The active flaps have a constant chord as they are manufactured in an extrusion process. The blades can be manufactured such that the flap is applied as an add-on to an existing blade or fully integrated into the design from the start. This paper explores how flaps would affect the design both as an "add-on" and completely integrated in the design. The method of actuation and the structural details of the flap are not included in this analysis.

The overall objective of the paper is to apply the developed aero-elastic optimization framework on the design of a blade, incorporating active trailing edge flaps. There is sufficient freedom in the design variables that the optimization can also incorporate bend-twist coupling. This will demonstrate how both passive and active load alleviation can be combined. The added value of the optimized "smart blade" design is thus shown through a comparison to an aero-elastically optimized design with no flaps.

\section{Analysis methods}

MDO was used to investigate how active flaps could improve performance and affect design. The optimization framework is described in Sect. 2.1. The parameterization of the blade is described in Sect. 2.2. The flap configuration and the DTU $10 \mathrm{MW}$ reference wind turbine (RWT) used in this study is described in Sect. 2.3. Finally, the details about the optimization are given in Sect. 2.4.

\subsection{Optimization framework}

The HAWTOpt 2 optimization framework (Zahle et al., 2016) is a MDO tool developed by DTU Wind Energy based on OpenMDAO (Gray et al., 2013). The tool is a python based code that couples finite element method cross-section analysis tool BEam Cross section Analysis Software (BECAS) (Blasques et al., 2016) with the aero-elastic tools HAWC2 (Larsen and Hansen, 2014) and HAWCStab2 (Hansen, 2004) to conduct aero-elastic analysis of wind turbine rotors. The workflow is shown graphically in Fig. 2. HAWC2 has a near wake model that can model the induced drag from flap deflection, but this was not used in this work. The analysis is coupled to the interior point optimization algorithm IPOPT (Wächter and Biegler, 2006).

The framework can simultaneously optimize the internal structure, the control strategy and the planform of the rotor. The loads are evaluated with reduced design load cases (DLCs) (Pavese et al., 2016), which is a simplification of the full set of DLCs defined in Hansen et al. (2015). From this, various load constraints (e.g. root flap-wise bending moment, tower top thrust) and tip deflection constraints can be evaluated. An envelope of bending loads is generated for the whole blade and then passed to BECAS to evaluate material failure constraints. The framework can evaluate the fatigue damage with a frequency domain model from HAWCStab2 (Tibaldi et al., 2015), but this was not used here for two reasons. First, this work focused on AEP maximization and not fatigue re- 


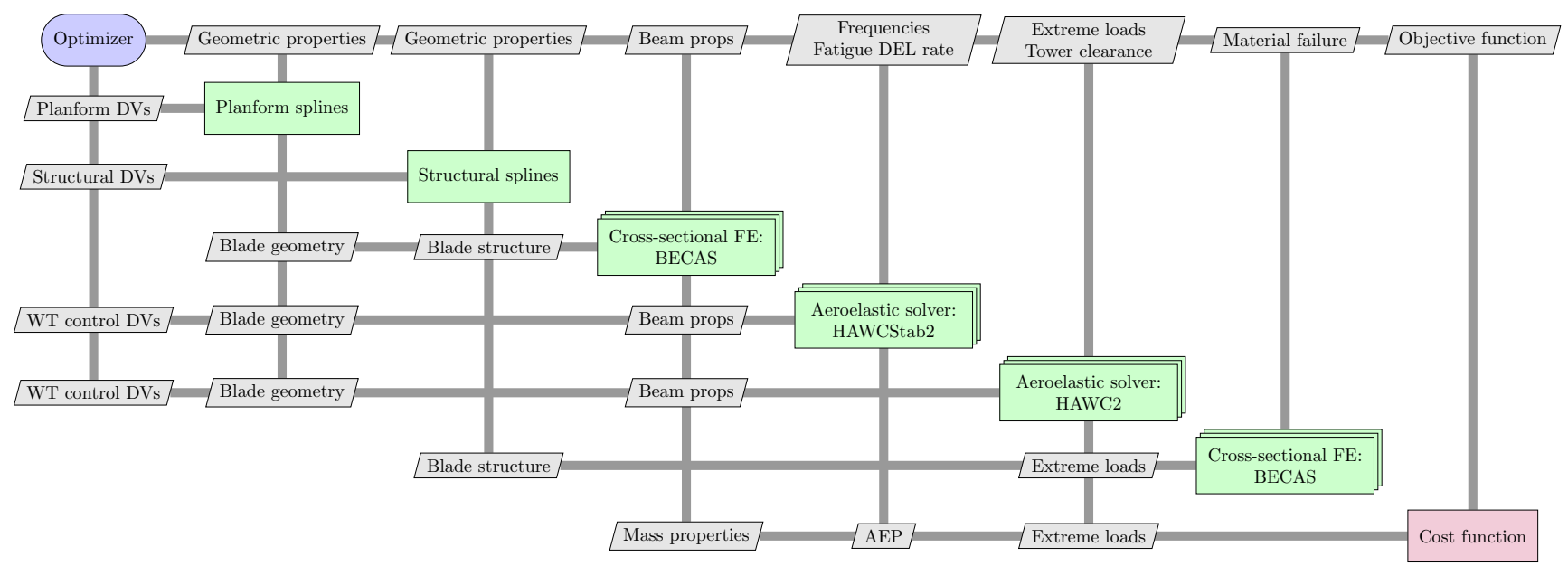

Figure 2. HAWTOpt2 workflow.

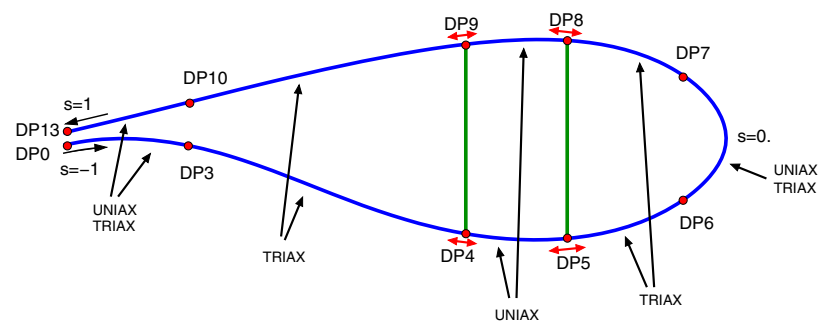

Figure 3. Cross-section definition.

duction. Second, the frequency domain model needs to be updated to include the effect of the flaps. More details on the framework are given in Zahle et al. (2016).

\subsection{Blade parameterization}

The blade planform is described in terms of distributions of chord, twist, relative thickness and pitch axis aft leading edge, the latter being the distance between the leading edge and the blade axis. The lofted shape of the blade is generated based on interpolation of a family of airfoils with different relative thicknesses.

The internal structure is defined from a number of regions that each cover a fraction of the cross sections along the blade. Each region consists of a number of materials that are placed according to a certain stacking sequence. Figure 3 shows a cross section in which the region division points (DPs) are indicated. The DP curves are described by a smooth spline as function of span that takes values between $s=-1$ and $s=1$, where $s=-1$ is located at the pressure side trailing edge, $s=0$ is at the leading edge and $s=1$ is located at the trailing edge suction side. Shear webs are associated with two specific DPs on the pressure and suction side and will move according to these points. The composite lay up is likewise described by a series of smooth splines de-
Table 1. Summary of DTU 10 MW RWT.

\begin{tabular}{ll}
\hline Rated power & $10 \mathrm{MW}$ \\
Rotor diameter & $178.3 \mathrm{~m}$ \\
Rated rotor speed & $9.6 \mathrm{rpm}$ \\
Rated wind speed & $11.4 \mathrm{~m} \mathrm{~s}^{-1}$ \\
Cut-in, cut-out wind speed & $4 \mathrm{~m} \mathrm{~s}^{-1}, 25 \mathrm{~m} \mathrm{~s}^{-1}$ \\
Gear box ratio & 50.0 \\
Pitch rate limit & $10^{\circ} \mathrm{s}^{-1}$ \\
\hline
\end{tabular}

scribing the thicknesses of individual layers. For more details on the parameterization see Dykes et al. (2017).

To accommodate a flap, the blade is manufactured with a flat back for the flap to be mounted upon. In this study, the presence of the flap was ignored in the structural analysis. However, previous work has shown that the flat back has structural benefits in wind turbine design (Barlas et al., 2016b).

\subsection{Reference wind turbine and flap description}

The design study is based on the DTU 10 MW RWT (Bak et al., 2013). The RWT is meant to be a $10 \mathrm{MW}$ off-shore, pitch regulated, wind turbine with conventional glass fiber rotor blades. The aerodynamic design is based on maximizing the $C_{P}$, so it is not aero-structurally optimal. The loads of this design were used as the constraints for the subsequent designs, so the optimization results here did not increase the loads. Some of the details of this design are shown in Table 1, for more details refer to Bak et al. (2013).

Figure 4 shows the placement of the flap used in this design study. Table 2 shows some of the performance details of this flap. A single set of flaps was used on the rotor between 65 and $95 \%$ of the span. In the optimization, the length of the blade is allowed to vary, but the relative span-wise placement 


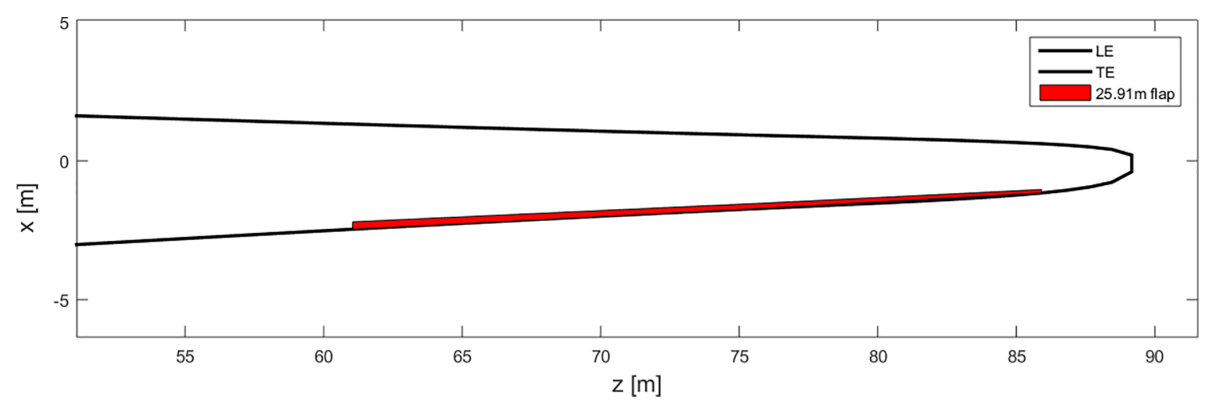

Figure 4. Flap placement.

Table 2. Summary of flap configuration.

\begin{tabular}{ll}
\hline Chord-wise extension & $10 \%$ \\
Deflection angle limits & $\pm 15^{\circ}$ \\
Span-wise length & $25.9 \mathrm{~m}(30 \%$ blade length) \\
Span-wise location & $59.59-85.80 \mathrm{~m}$ (from blade root) \\
Airfoil & FFA-W3-241 \\
Max $\Delta C_{l}$ & 0.6 \\
Deflection rate limit & $100^{\circ} \mathrm{s}^{-1}$ \\
Actuator time constant & $100 \mathrm{~ms}$ \\
\hline
\end{tabular}

of the flaps remains constant. Multiple sets of flaps along the blade could provide finer control of the loading along the span, but this was not considered in this work. The flap deflection was based on the wind speed at hub height. The wind speed was passed through a low-pass filter. Thus, the flap deflection was quasi-static. This quasi-static flap actuation was only used below rated conditions, while the use of flaps for attenuating fatigue loads occurs in above rated conditions, so these two functions do not interfere.

\subsection{Optimization problem statement}

The optimization is based on solving the problem given in 1 . The optimization is essentially a maximization of AEP without increasing the loads on the platform. This is a common industrial design problem when a manufacturer wants to develop a new set of blades for a platform already in existence.

$$
\begin{array}{cl}
\underset{\boldsymbol{x}_{p}, \boldsymbol{x}_{s}, \boldsymbol{x}_{\mathrm{oper}}}{\operatorname{minimize}} & f\left(\left\{\mathbf{x}_{p}, \mathbf{x}_{s} \mathbf{x}_{\mathrm{oper}}, \boldsymbol{p}, w\right)\right. \\
\text { subject to } & \boldsymbol{g}\left(\boldsymbol{x}_{p}\right) \leq \mathbf{0}, \\
& \boldsymbol{h}_{g}\left(\mathbf{x}_{s}\right) \leq \mathbf{0}, \\
& \boldsymbol{h}_{s}\left(\boldsymbol{x}_{s}\right) \leq \mathbf{0}, \\
& \boldsymbol{k}\left(\left\{\boldsymbol{x}_{p}, \boldsymbol{x}_{s}\right\}\right) \leq \mathbf{0},
\end{array}
$$

where

$f\left(\left\{\boldsymbol{x}_{p}, \boldsymbol{x}_{s}, \boldsymbol{x}_{\mathrm{oper}}\right\}, \boldsymbol{p}\right)=\frac{\mathrm{AEP}(\{\mathbf{0}, \mathbf{0}, \mathbf{0}\}, \boldsymbol{p})}{\operatorname{AEP}\left(\left\{\boldsymbol{x}_{p}, \boldsymbol{x}_{s}, \boldsymbol{x}_{\mathrm{oper}}\right\}, \boldsymbol{p}\right)}$.

The design variables used in this optimization are shown in Table 3. They include a mix of planform, internal structure and control design variables. The critical design variable is the blade length. Load reduction strategies are used to allow the rotor to increase in size without increasing the total loads.

The constraints used in the problem are shown in Table 4.

\section{Results}

To understand the following results it is helpful to understand how an aero-elastically optimal blade differs from a $C_{P}$ optimized blade. Overall, aero-elastic optimization reduces the distributed loading so it has room to increase the power with a larger swept area. This can be achieved by simply reducing the thrust loading, because near peak $C_{P}$ it will only cause relatively small reductions in the $C_{P}$. So aeroelastically optimal blades typically have lower loading, lower $C_{P}$ and larger swept area. Additional improvements can be achieved by changing the blade configuration under conditions where peak loads occur (i.e. at rated wind speed). This is referred to as load alleviation; examples are bend-twist coupling, collective pitch for peak shaving and other load alleviation strategies. Flaps are just one example of load alleviation strategies, but they can also be used in other conditions to extract more AEP by increasing the loads.

The analysis is based on applying the HAWTOpt2 frame work to solve the problem in Sect. 2.4 and then comparing the results. In this work four different optimized designs were generated to evaluate the performance of the flaps:

- DTU 10MW RWT with flaps. This is the original DTU 10 MW RWT with flaps attached. Only the flap deflection was varied in the design optimization. This solution represents a flap add-on for a $C_{P}$ optimized design.

- Baseline. This is a load neutral aero-elastic design optimization of the original DTU 10 MW RWT without flaps. In this optimization, no flaps were used. This design represents the best rotor performance that can be achieved without flaps.

- Baseline with flaps. Here, flaps were attached to the rotor design from the baseline optimization. In this optimization only the flap deflection was optimized, the rest of the rotor design is identical to the original baseline 
Table 3. Summary of design variables.

\begin{tabular}{lcl}
\hline Parameter & No. of DVs & Comment \\
\hline Chord & 6 & - \\
Twist & 5 & Root twist fixed \\
Relative thickness & 3 & Root and tip relative thickness fixed \\
Blade prebend & 4 & - \\
Blade pre-cone & 1 & - \\
Blade length & 1 & - \\
Tip-speed ratio & 1 & - \\
Trailing edge uniax & 2 & Pressure/suction side \\
Trailing edge triax & 2 & Pressure/suction side \\
Trailing panel triax & 2 & Pressure/suction side \\
Spar cap uniax & 4 & Pressure/suction side \\
Leading panel triax & 2 & Pressure/suction side \\
Leading edge uniax & 2 & Pressure/suction side \\
Leading edge triax & 2 & Pressure/suction side \\
DP4 & 5 & Pressure side spar cap position/rear web attachment \\
DP5 & 5 & Pressure side spar cap position/front web attachment \\
DP8 & 5 & Suction side spar cap position/front web attachment \\
DP9 & 5 & Suction side spar cap position/rear web attachment \\
Flap angle & 5 & Flap angle at five wind speeds \\
\hline Total & 65 & \\
\hline
\end{tabular}

Table 4. Summary of optimization constraints.

\begin{tabular}{lll}
\hline Constraint & Value & Comment \\
\hline max(chord) & $<6.2 \mathrm{~m}$ & Maximum chord limited for transport. \\
$\max ($ prebend) & $<6.2 \mathrm{~m}$ & Maximum prebend limited for transport. \\
$\max ($ rotor cone angle) & $>-5^{\circ}$ & - \\
min(relative thickness) & $>0.24$ & Same airfoil series as used on the DTU 10 MW RWT. \\
$\min ($ material thickness) & $>0.0$ & Ensure FFD splines do not produce negative thickness. \\
$t / w_{\text {spar cap }}$ & $>0.08$ & Basic constraint to avoid spar cap buckling. \\
min(tip tower distance) & $>$ ref value & DLC1.3 operational tip deflection cannot exceed that of the \\
& $<$ ref value & DTU 10 MW RWT. \\
Blade root flap-wise moments $(\mathrm{MxBR})$ & DLB loads cannot exceed starting point. \\
Blade root edgewise moments $(\mathrm{MyBR})$ & $<$ ref value & DLB loads cannot exceed starting point. \\
Tower bottom fore-aft moments $(\mathrm{MxTB})$ & $<$ ref value & DLB loads cannot exceed that starting point. \\
Rotor torque & $<$ ref value & Ensure that the rotational speed is high enough below rated to not \\
& & exceed generator maximum torque. \\
Blade mass & $<1.01 \times$ ref value & Limit increase in blade mass to maintain equivalent production costs. \\
Blade mass moment & $<1.01 \times$ ref value & Limit increase in blade mass moment to minimize edgewise fatigue. \\
Lift coefficient @ $r / R=[0.5-1]$. & $<1.35$ & Limit operational lift coefficient to avoid stall for turbulent inflow \\
& & conditions. \\
Ultimate strain criteria & $<1.0$ & Aggregated material failure in each section for 12 load cases. \\
Flap angle & $-15.0 \geq \beta \geq 15.0$ & Flap angle stays within 15 bounds \\
\hline
\end{tabular}

optimization. This represents an add-on solution for an aero-elastically optimized rotor.

- Co-design. This is a load neutral aero-elastic design optimization of the original DTU 10 MW RWT with flaps. In this optimization both the flaps and the rotor design were optimized simultaneously. This design represents an fully integrated design where the rotor is designed for flaps.

Table 5 shows some of the results from the optimization studies. For aero-elastically optimized blades, the flaps can provide a $1 \%$ improvement in AEP, whereas on a $C_{P}$ optimized design they can only give a $0.51 \%$ improvement. Aero-elastic optimization reduces the loading, thus providing 


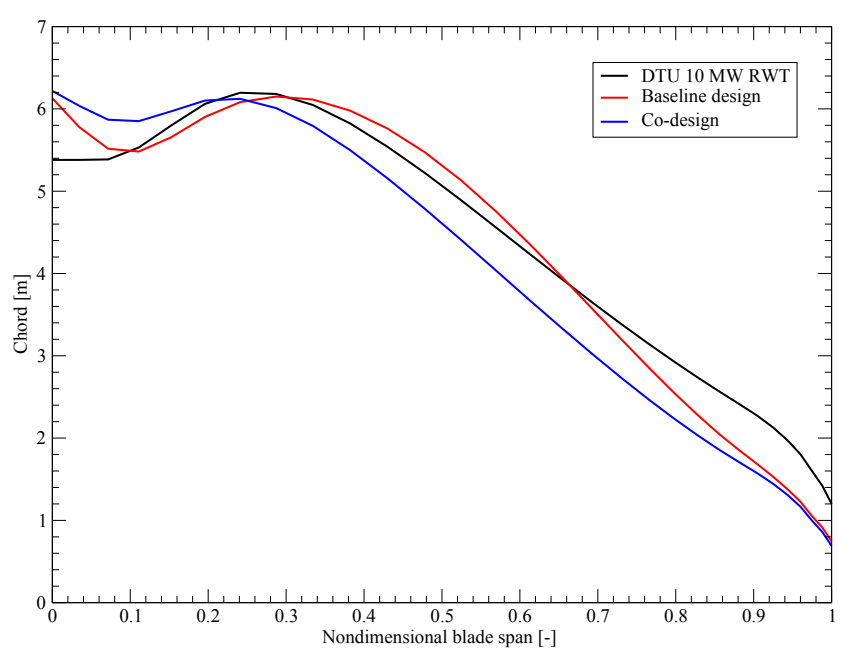

(a) Chord

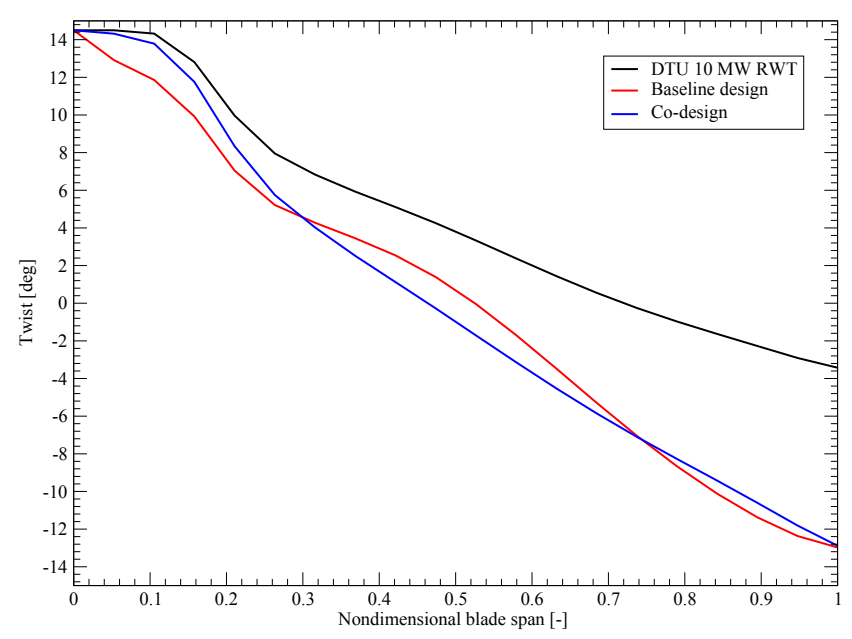

(b) Twist

Figure 5. Rotor planform design.

Table 5. Summary of optimization results.

\begin{tabular}{lrrr}
\hline Wind turbine design & $\begin{array}{r}\text { Gain in } \\
\text { AEP }(\%)\end{array}$ & $\begin{array}{r}\text { Blade } \\
\text { length } \\
(\mathrm{m})\end{array}$ & $\begin{array}{r}\text { Tip } \\
\text { speed } \\
\text { ratio } \\
(-)\end{array}$ \\
\hline DTU 10 MW RWT with flaps & 0.51 & 86.37 & 7.5 \\
Baseline & 14.65 & 101.25 & 9.12 \\
Baseline with flaps & 15.68 & 101.25 & 9.12 \\
Co-design & 15.69 & 101.69 & 8.59 \\
Co-design without flaps & 13.93 & 101.69 & 8.59 \\
\hline
\end{tabular}

the flap with more room to generate more power through increased loading. This indicates that flaps may provide larger benefits for rotors with lower specific power. The similar performance between the "baseline with a flap" and co-design indicates that for this case there is little benefit designing both the blade and the flap deflection simultaneously. Furthermore, add-on solutions should be just as effective as integrated designs.

The fact that the base line with flaps achieved nearly the same performance as the co-design was not expected. Typically, one expects better designs with more design freedom. Furthermore, the optimization algorithm chooses design variables that would degrade the performance without flaps because it can compensate by using more flap actuation. Further investigation is needed to determine the reasons why. There are many possibilities: the optimizations may not have been completely converged; there are multiple local minimum solutions; the design space is relatively flat, where multiple configurations give similar performance.

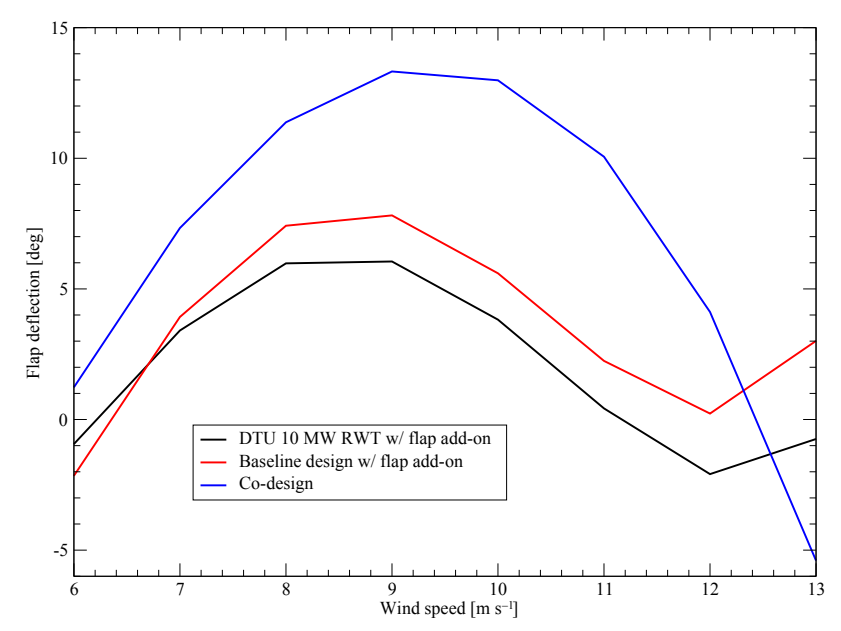

Figure 6. Flap deflection.

Both the aero-elastically optimized blades achieved much longer blade lengths and a faster tip-speed ratio. The codesign achieved a $44 \mathrm{~cm}$ longer blade than the baseline, so it gets even more AEP from swept area. The tip-speed ratio for the co-design is lower than the baseline. There are a couple possible reasons for this: the flap actuation could be increasing the profile drag, thus increasing the aerodynamic penalty of higher tip speeds. A faster tip speed can cause rated rotor speed to occur before peak loads; once this occurs the tipspeed ratio drops and the rotor can shed loads. This is a peak shaving strategy that is commonly exploited in HAWTOpt2 results. Thus, a second reason a slower tip-speed ratio occurs in the co-design is that the optimization prefers flap actuation over reduced tip-speed ratios, for peak shaving. A high tip speed would lead to increased erosion and noise, but these 


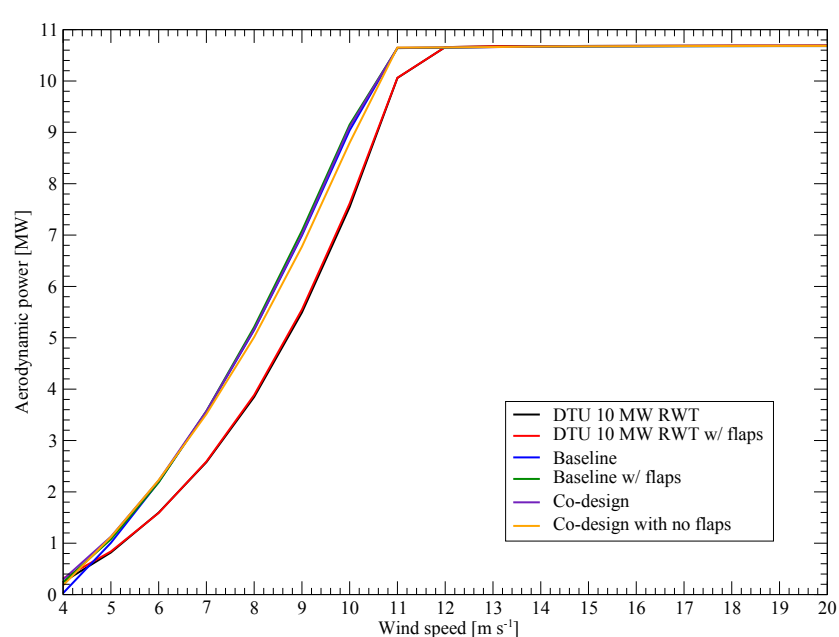

(a) Total power

Figure 7. Aerodynamic power.

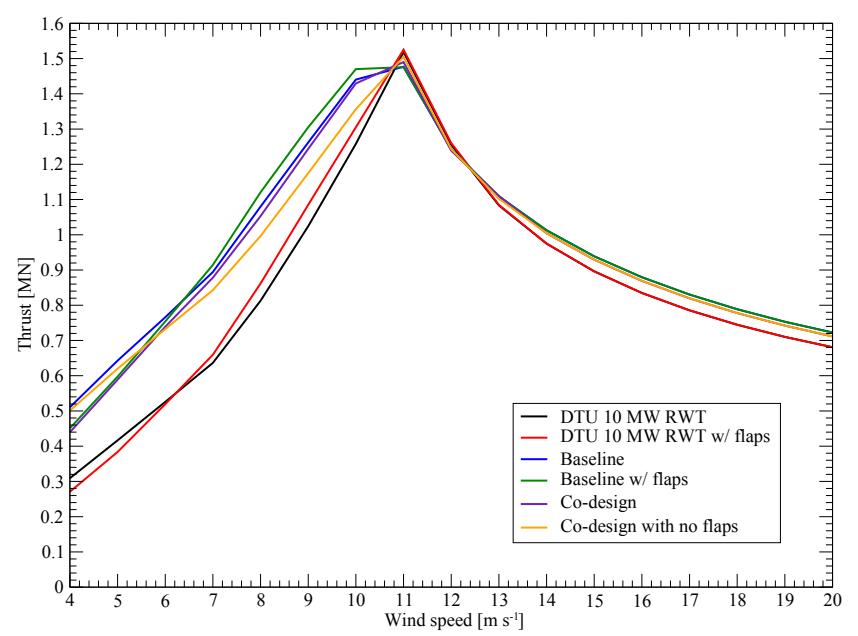

(a) Total thrust

Figure 8. Aerodynamic thrust.

issues were ignored to assess how flaps would affect the optimal tip-speed ratio.

Figure 5 shows the planform for both the baseline and codesign. The two aero-elastically optimal blades both appear to have a more aggressive twist distribution (i.e. twisted towards higher loading and stall). However, it will be shown later that these blades undergo increased torsional deflection and need the aggressive twist to compensate.

Both aero-elastic designs had lower solidity towards the tip. In the co-design, the presence of the flaps in the optimization leads to a smaller solidity and slightly more aggressive twist distribution further inboard. There is an aero-elastic response to the flap deflection, where it will also deform the blade. One may think that the different inboard configura-

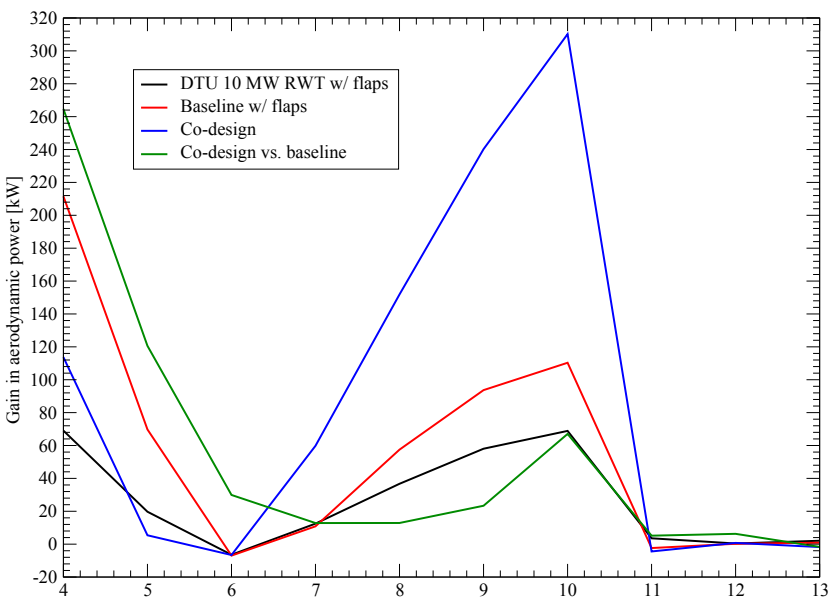

(b) Power gained from flaps

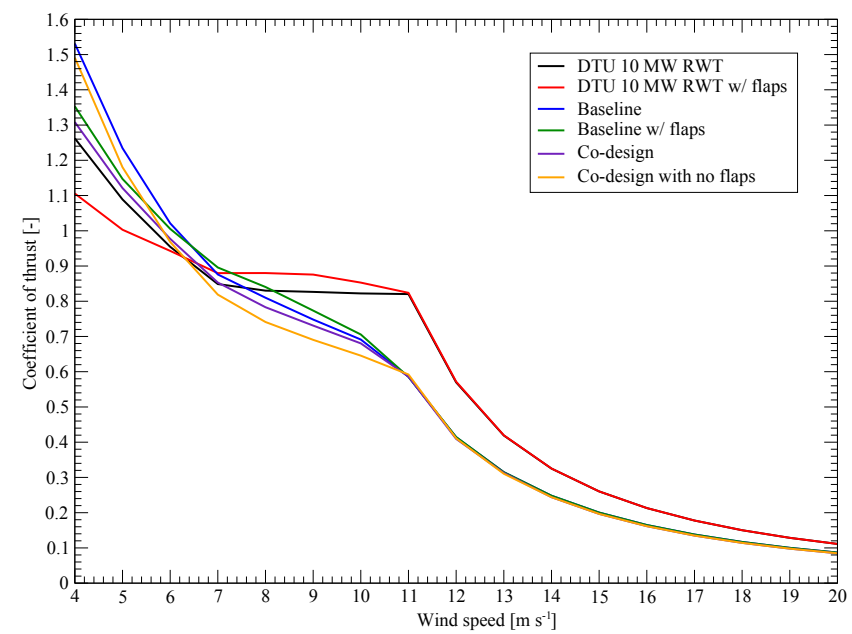

(b) Coefficient of thrust

tion is compensating for this deformation, but the results will show that enhances the aero-elastic effect of the flap.

Figure 6 shows the optimal flap deflection schedule for the three cases with a flap. In all cases the flap deflection is relatively small at low wind speeds because here the turbine is already operating at high $C_{T}$ values and can generate more power with lower loading. In the constant $C_{P}$ tracking region, the flap is able to harvest more power with higher loading. Then approaching rated conditions, the flap angle decreases to attenuate the peak loads. The baseline flap schedule is similar to the original DTU $10 \mathrm{MW}$ RWT, except the lower loading affords more aggressive flap deflections to extract more power. In the co-design the optimization develops a blade design that relies on much larger flap deflection angles. 
Figure 7a shows the power of the optimized designs and the effect of the flap is shown in Fig. 7b by subtracting the power of the corresponding non-flap blade performance. The results show that the flap adds power in two distinct regions. The first is between 4 and $5 \mathrm{~m} \mathrm{~s}^{-1}$, where the turbine is operating at constant speed. Here the flap is reducing the loading to reduce the high $C_{T}$. Then between 8 and $10 \mathrm{~m} \mathrm{~s}^{-1}$ the flap is able to extract more power by increasing the loading.

Figure 8 shows the thrust and coefficient of thrust $\left(C_{T}=\right.$ $\left.2 T /\left(\rho A V^{2}\right)\right)$ from steady-state simulations of the optimized rotor. It is clear that peak loads occur at $11 \mathrm{~m} \mathrm{~s}^{-1}$. The $C_{T}$ for all the flap equipped rotors experience a shaper drop between 10 and $11 \mathrm{~m} \mathrm{~s}^{-1}$; this is evidence that the flaps are being used for peak shaving. Comparing the $C_{T}$ between the two codesign simulations, it is clear that the optimization uses the flaps more for peak shaving than in the baseline optimization.

Passive load alleviation is an important innovation for blade design. The HAWTOpt 2 framework will produce aeroelastic tailored blades that will passively torsion to shed loads (Zahle et al., 2016). This work looked at how passive load alleviation could be combined with flaps. Figure 9 shows the torsional deformation at the tip over a range of wind speeds in steady uniform conditions. In the baseline optimization, the aero-elastic tailoring is optimized without flaps; in the co-design the optimization can vary both the flap angles and the blade design. Comparing these two designs it is clear that both blades had similar amounts of torsional deformation, thus, active flaps complement passive load alleviation strategies. The flap actuation in Fig. 6 show high-order actuation with increasing loads, whereas passive strategies can only achieve linear load alleviation.

The results also show that flaps cause additional torsional deformation because of increased aerodynamic moments on the blade. This suggests that the active load alleviation needs to be designed in conjunction with the flaps.

Figure 10 shows the distributed aerodynamic forces for the DTU 10 MW RWT with and without the flaps. The loading caused by the flaps is clear in the $y$ direction (i.e. normal to the chord), yet it is quite small in the $x$ direction. In this design the effect of the flaps can be superimposed on the original aerodynamic loading.

Figure 11 shows the distributed aerodynamic forces for the baseline rotor, with and without flaps. The loading here is more complicated than in Fig. 10 because the blade is so much more torsionally flexible. The increased moment caused by the flaps is twisting the blades, this is also seen in the loading inboard of the flaps. This is evidence that the flaps can also redistribute the loads along the blade through elastic torsion of the blade.

Figure 12 compares the co-design with flaps to the baseline without flaps. This highlights that including flaps in the optimization leads to different behaviour in the final design. In Fig. 12b the design has a much greater redistribution of loading along the blade compared to Fig. 11. Then in Fig. 12a the co-design is able to increase the overall driving forces in

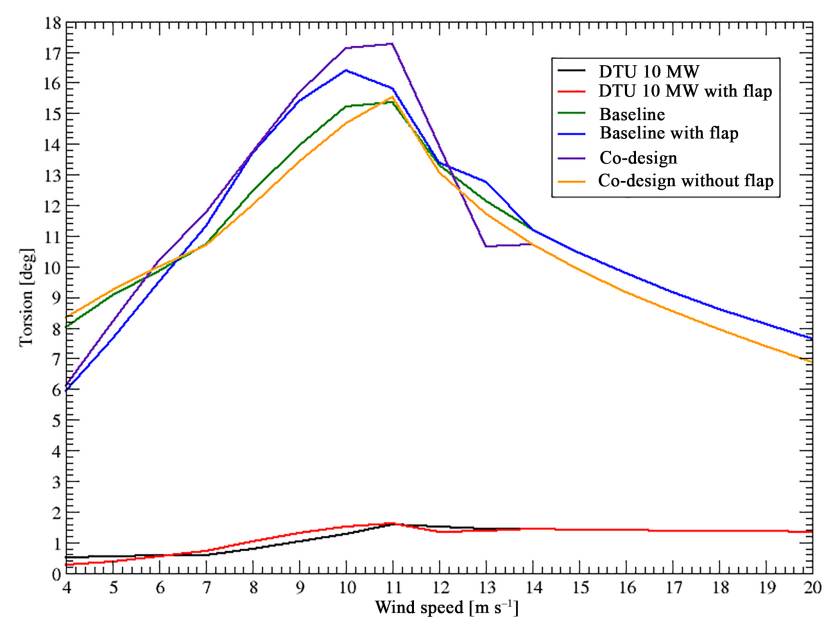

Figure 9. Blade torsion.

areas where the flaps are not installed. Thus, an integrated design approach is able to better exploit the different ways the flaps can be used to extract power.

Figures 11 and 12 show that the effect of flaps on aeroelastically optimal wind turbine blades is a very complicated. The flaps can change the loading both in the location where they are installed and further inboard due to changing aerodynamic moment and the torsional flexibility. For these blades, simply superimposing additional forces from the flaps onto the original blade loading would not properly capture the true effect of the flaps. The greatest benefit from flaps occurs for aero-elastically optimal blades; however, the flap control strategies need to be designed with full aeroelastic analysis to accurately predict the true response. This highlights the importance of integrated design tools for advanced rotor design.

\section{Conclusions}

This research investigated how flaps, operated in a quasistatic manner, could be used to increase the AEP of a wind turbine. MDO was used to optimize the flap angle and multiple blade designs. For $C_{P}$ optimized rotor designs, the loading is already quite high, so the flaps could only achieve a $0.51 \%$ improvement in AEP. Aero-elastically optimal blades typically have lighter loading so flaps can be better exploited to extract more energy, giving a $1 \%$ improvement in AEP.

The flaps would extract extra energy at very low wind speeds by reducing the loading. They would then extract more energy in the $C_{P}$ tracking region by increasing the loading. As the wind turbine approached peak loads, the flaps angle would decrease to shave the peak loads. This meant that the flaps would be actuated in a quadratic or higher-order actuation schedule. This shows that flaps are complementary 


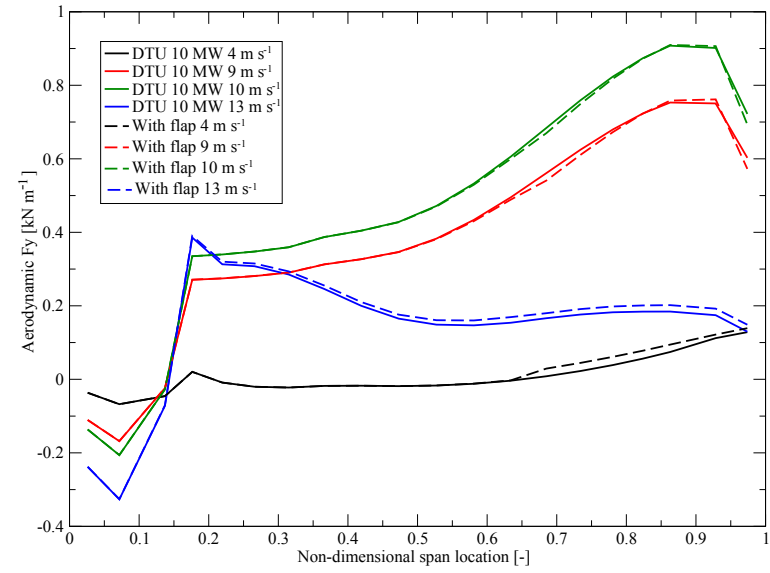

(a) $F_{x}$

Figure 10. DTU 10 MW RWT aerodynamic blade forces.

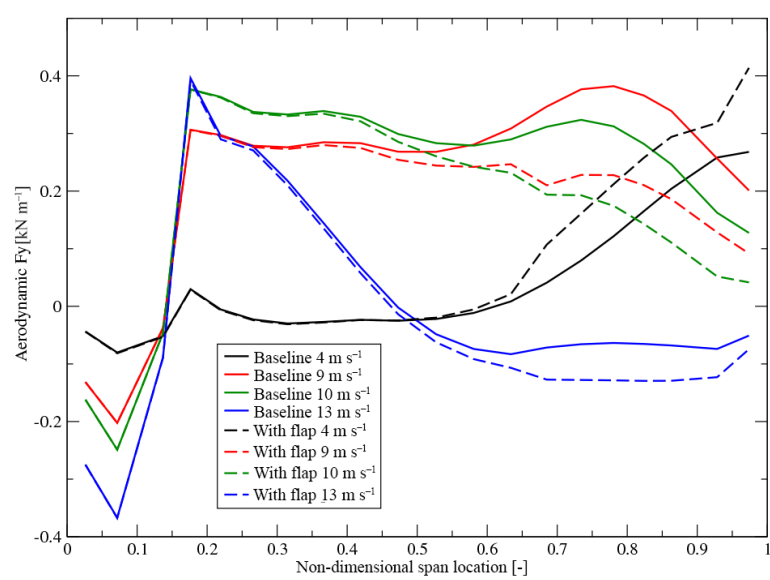

(a) $F_{x}$

Figure 11. Baseline aerodynamic blade forces.

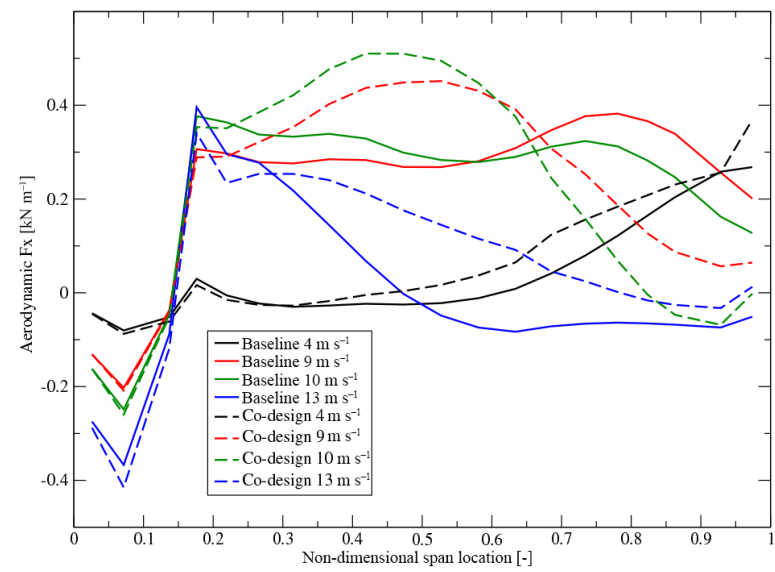

(a) $F_{x}$

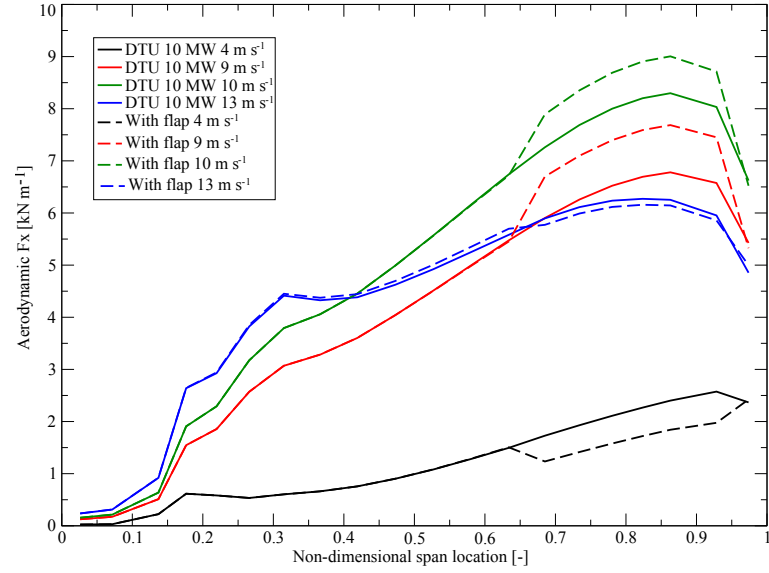

(b) $F_{y}$

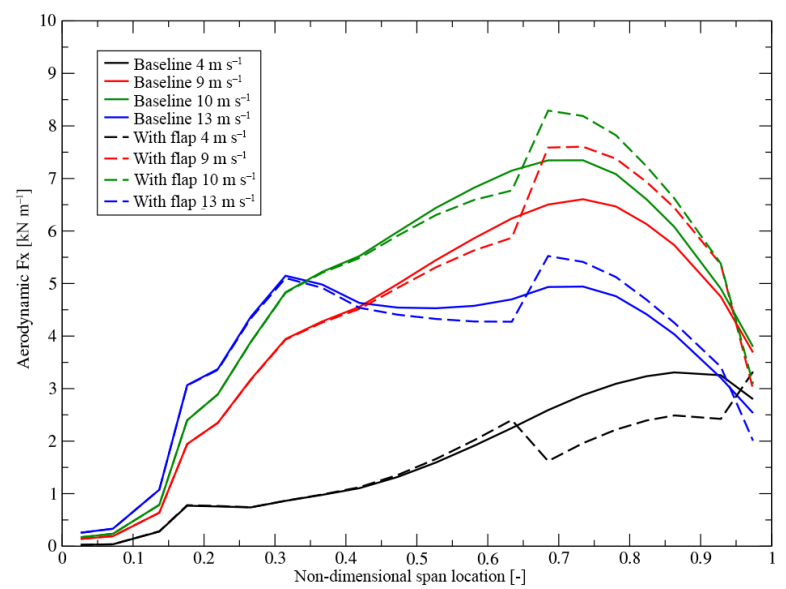

(b) $F_{y}$

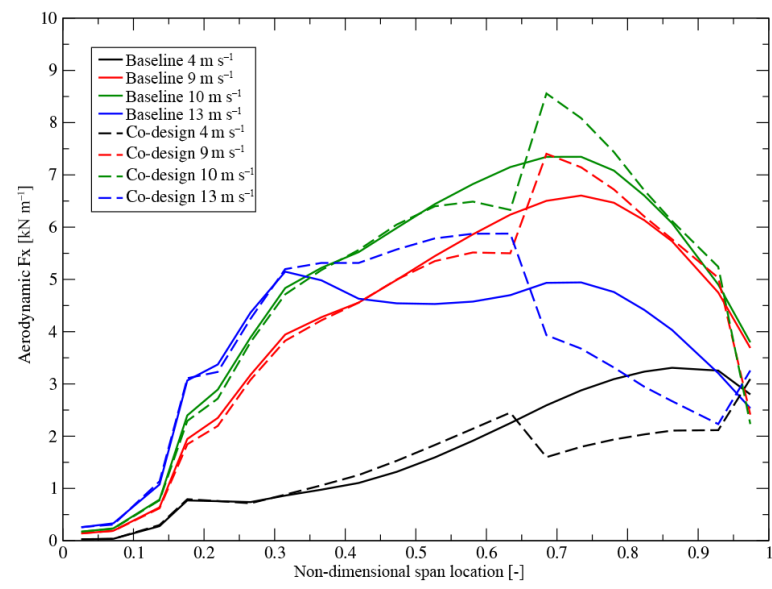

(b) $F_{y}$

Figure 12. Co-design vs. baseline aerodynamic blade forces. 
with other passive load alleviation strategies that only produce a linear load alleviation.

Flaps introduce a complicated aero-elastic response in aero-elastically optimal blades because they are much more flexible in torsion and flap deflection increases the aerodynamic moment forces. The results shows the flap deflection will twist the blade inboard of the flaps, changing the forces there as well. In the co-design, the optimization was able to find configurations where the flaps contributed more to driving forces inboard of the flaps. Thus, optimal rotor design with flaps cannot be achieved by simply superimposing the additional loading of the flaps. Thus, full aero-elastic simulations and integrated design techniques are required to develop these smart rotors.

Data availability. The data and results contained in this article can be obtained by contacting the author.

Competing interests. The authors declare that they have no conflict of interest.

Acknowledgement. The work was funded by the Danish Development and Demonstration Program (EUDP) under contract J.nr. 64015-0069, for the research project "INDUFLAP2 Full scale demonstration of an active flap system for wind turbines".

Edited by: Gerard J. W. van Bussel

Reviewed by: two anonymous referees

\section{References}

Ashuri, T., Zaaijer, M., Martins, J., van Bussel, G., and van Kuik, G.: Multidisciplinary design optimization of offshore wind turbines for minimum levelized cost of energy, Renew. Energ., 68, 893-905, https://doi.org/10.1016/j.renene.2014.02.045, 2014.

Bak, C., Zahle, F., Bitsche, R., Kim, T., Yde, A., Henriksen, L. C., Natarajan, A., and Hansen, M. H.: Description of the DTU 10 MW Reference Wind Turbine, Tech. rep., Technical University of Denmark, Institute for Wind Energy, Denmark, 2013.

Barlas, T. K.: Active aerodynamic load control on wind turbine blades: Aeroservoelastic modelling and wind tunnel experiments, $\mathrm{PhD}$ thesis, TU Delft, available at: $\quad$ https://repository.tudelft.nl/islandora/object/uuid\% 3A6918a4d0-2b75-44e6-bf33-2822d7c2d264 (last access: May 2018), 2011.

Barlas, T. K. and van Kuik, G. A. M.: Review of state of the art in smart rotor control research for wind turbines, Prog. Aerosp. Sci., 46, 1-27, 2010.

Barlas, T. K., Pettas, V., Gertz, D., and Madsen, H. A.: Extreme load alleviation using industrial implementation of active trailing edge flaps in a full design load basis, J. Phys. Conf. Ser., 753, 042001, https://doi.org/10.1088/1742-6596/753/4/042001, 2016a.
Barlas, T. K., Tibaldi, C., Zahle, F., and Madsen, H. A.: Aeroelastic Optimization of a $10 \mathrm{MW}$ Wind Turbine Blade with Active Trailing Edge Flaps, in: 34th Wind Energy Symposium, AIAA SciTech Forum, San Diego, California, USA, 2016 b.

Bergami, L.: Adaptive Trailing Edge Flaps for Active Load Alleviation in a Smart Rotor Configuration, $\mathrm{PhD}$ thesis, Technical University of Denmark, Denmark, 2013.

Bernhammer, L. O., van Kuik, G. A. M., and Breuker, R. D.: How far is smart rotor research and what steps need to be taken to build a full-scale prototype?, J. Phys. Conf. Ser., 555, 012008, https://doi.org/10.1088/1742-6596/555/1/012008, 2014.

Blasques, J. P., Bitsche, R. D., Fedorov, V., and Lazarov, B. S.: Accuracy of an efficient framework for structural analysis of wind turbine blades, Wind Energy, 19, 1603-1621, https://doi.org/10.1002/we.1939, 2016.

Bottasso, C., Campagnolo, F., and Croce, A.: Multi-disciplinary constrained optimization of wind turbines, Multibody Syst. Dyn., 27, 21-53, https://doi.org/10.1007/s11044-011-9271-x, 2012.

Castaignet, D., Barlas, T., Buhl, T., Poulsen, N., Wedel-Heinen, J., Olesen, N., Bak, C., and Kim, T.: Full-scale test of trailing edge flaps on a Vestas V27 wind turbine: active load reduction and system identification, Wind Energy, 17, 549-564, https://doi.org/10.1002/we.1589, 2014.

Chen, Z., Stol, K., and Mace, B.: Wind turbine blade optimisation with individual pitch and trailing edge flap control, Renew. Energ., 103, 750-765, https://doi.org/10.1016/j.renene.2016.11.009, 2017.

Dykes, K., Rethore, P.-E., Zahle, F., McWilliam, M., Graf, P., Ning, A., and McWilliam, M.: Fused-Wind, available at: http: //www.fusedwind.org/ (last access: May 2018), 2017.

Fischer, G. R., Kipouros, T., and Savill, A. M.: Multiobjective optimisation of horizontal axis wind turbine structure and energy production using aerofoil and blade properties as design variables, Renew. Energ., 62, 506-515, https://doi.org/10.1016/j.renene.2013.08.009, 2014.

Fuglsang, P. and Madsen, H. A.: Optimization method for wind turbine rotors, J. Wind Eng. Ind. Aerod., 80, 191-206, 1999.

Gray, J., Moore, K. T., Hearn, T. A., and Naylor, B. A.: Standard Platform for Benchmarking Multidisciplinary Design Analysis and Optimization Architectures, AIAA J., 51, 2380-2394, 2013.

Hansen, M. H.: Aeroelastic Stability Analysis of Wind Turbines Using an Eigenvalue Approach, Wind Energy, 7, 133-143, 2004.

Hansen, M. H., Thomsen, K., Natarajan, A., and Barlas, T. K.: Design Load Basis for onshore turbines - Revision 00, Tech. rep., Danish Technical University, Denmark, 2015.

Johnson, S. J., Baker, J. P., van Dam, C. P., and Berg, D.: An overview of active load control techniques for wind turbines with an emphasis on microtabs, Wind Energy, 13, 239-253, 2010.

Larsen, T. J. and Hansen, A. M.: How 2 HAWC2, the user's manual, Ris $\varnothing-r-1597(v e r .4-5)(E N)$, Ris $\varnothing$ National Laboratory, available at: www.hawc2.dk (last access: May 2018), 2014.

Madsen, H. A., Andersen, T. L., Bergami, L., Jørgensen, J. E., Garolera, A. C., Holbøll, J., Schettler, T., Michels, P., Schoebel, M., Heisterberg, M., and Christensen, M.: Towards an industrial manufactured morphing trailing edge flap system for wind turbines, European Wind Energy Association - EWEA, 2014.

Madsen, H. A., Barlas, T. K., and Løgstrup, T. A.: A morphing trailing edge flap system for wind turbine blades, in: Proceedings of 
the 7th ECCOMAS Thematic Conference on Smart Structures and Materials (SMART 2015), 7, Ponta Delgada, Portugal, 2015.

McWilliam, M. K.: Towards Multidisciplinary Design Optimization Capability of Horizontal Axis Wind Turbines, PhD thesis, University of Victoria, 2015.

Merz, K. O.: Rapid optimization of stall-regulated wind turbine blades using a frequency-domain method: Part 1, loads analysis, Wind Energy, 18, 1703-1723, https://doi.org/10.1002/we.1786, 2015a.

Merz, K. O.: Rapid optimization of stall-regulated wind turbine blades using a frequency-domain method: Part 2, cost function selection and results, Wind Energy, 18, 955-977, https://doi.org/10.1002/we.1738, 2015b.

Ning, A., Damiani, R., and Moriarty, P.: Objectives and Constraints for Wind Turbine Optimization, J. Sol. Energ.-T. ASME, 136, 041010, https://doi.org/10.1115/1.4027693, 2014.

Pavese, C., Tibaldi, C., Larsen, T. J., Kim, T., and Thomsen, K.: Reduced Design Load Basis for Ultimate Blade Loads Estimation in Multidisciplinary Design Optimization Frameworks, J. Phys. Conf. Ser., 753, 062005, https://doi.org/10.1088/17426596/753/6/062005, 2016.

Smit, J., Bernhammer, L. O., Navalkar, S. T., Bergami, L., and Gaunaa, M.: Sizing and control of trailing edge flaps on a smart rotor for maximum power generation in low fatigue wind regimes, Wind Energy, 19, 607-624, https://doi.org/10.1002/we.1853, 2016.
Tibaldi, C., Henriksen, L. C., Hansen, M. H., and Bak, C.: Wind turbine fatigue damage evaluation based on a linear model and a spectral method, Wind Energy, 19, 1289-1306, https://doi.org/10.1002/we.1898, 2015.

van Wingerden, J. W., Hulskamp, A., Barlas, T., Houtzager, I., Bersee, H., van Kuik, G., and Verhaegen, M.: TwoDegree-of-Freedom Active Vibration Control of a Prototyped "Smart" Rotor, IEEE T. Contr. Syst. T., 19, 284-296, https://doi.org/10.1109/TCST.2010.2051810, 2011.

Wächter, A. and Biegler, L. T.: On the implementation of an interior-point filter line-search algorithm for largescale nonlinear programming, Math. Program., 106, 25-57, https://doi.org/10.1007/s10107-004-0559-y, 2006.

Zahle, F., Tibaldi, C., Pavese, C., McWilliam, M., Blasques, J. P. A. A., and Hansen, M. H.: Design of an aeroelastically tailored $10 \mathrm{MW}$ wind turbine rotor, J. Phys. Conf. Ser., 753, https://doi.org/10.1088/1742-6596/753/6/062008, 2016. 